\title{
Global change impacts on the Upper Danube Catchment (Central Europe): a study of participatory modeling
}

\author{
Roland Barthel $^{1} \cdot$ Roman Seidl $^{2} \cdot$ Darla Nickel $^{3} \cdot$ Hannah Büttner ${ }^{4,5}$
}

Received: 23 March 2015/Accepted: 28 October 2015/Published online: 12 December 2015

(c) The Author(s) 2015. This article is published with open access at Springerlink.com

\begin{abstract}
Participatory modeling (PM) has become an essential concept in environmental impact assessment and planning in the field of water resources. In this paper, we focus on the use of PM to support the development of the integrated regional modeling system DANUBIA as a scientific concept to analyze the previously unknown impacts of global change, i.e., the combined effects of climate, demographic, economic, social and ecological change, on the Upper Danube Catchment (Germany). We use this case study to examine the specific conditions for PM in the field of complex integrated models on a regional scale. We describe the stepwise PM process and discuss the respective results, focusing on (1) the stakeholder dialogue's contribution in supporting the development of new,
\end{abstract}

Editor: Nicolas Dendoncker.

Roland Barthel

roland.barthel@gvc.gu.se

Roman Seidl

roman.seidl@env.ethz.ch

Darla Nickel

nickel@difu.de

Hannah Büttner

mail@hannahbuettner.de

1 Department of Earth Sciences, University of Gothenburg, Gothenburg, Sweden

2 Department of Environmental Systems Science, Transdisciplinary Lab (TDLab), ETH Zurich, Zurich, Switzerland

3 Deutsches Institut für Urbanistik (Difu), Berlin, Germany

4 IFOK GmbH, Bensheim, Germany

5 Dr. Hannah Büttner: Integrative Dialogue, Herrsching am Ammersee, Germany complex modeling systems, particularly on a regional scale, (2) conditions of stakeholder involvement in issues related to the distant future, such as climate change impacts on regional water availability, and (3) limitations of PM and scientists' motivation to carry out participatory research at all. We conclude that the PM process was not entirely successful in improving the scientific quality and practical applicability of the developed models because the process goals were manifold and overambitious, and the definition of the problem of "global change impacts on a regional scale" was too weak and uncertain to allow for a clear common objective of modelers and stakeholders. We claim that there is a lack of incentives for scientists, particularly natural scientists, to commit to PM activities.

Keywords Participatory modeling - Global change · Decision support - Integrated modeling - Regional scale . Upper Danube Catchment · DANUBIA · GLOWADanube $\cdot$ Water resources $\cdot$ Water supply

\section{Introduction}

\section{Terminology}

To clarify the usage of terminology in this paper, we understand participatory modeling (PM) as an activity that involves modelers who collaborate with partners outside the scientific arena to develop and apply models, in the context of solving or conceptualizing a problem of practical relevance. The term modelers refers here to scientists who develop, modify, and apply models as a central part of their academic research. The term stakeholders is broadly used to refer to those members of society whose interests are affected by a development, problem or project. In this 
article, the term is most often used in a narrower sense to describe non-scientists who are more or less actively involved in a PM process, including (1) potential and anticipated users of the models in question, (2) decision makers, that is, those who make or could make decisions based on the model results, and (3) experts working for ministries, agencies, consultancy firms, and private companies who can provide useful knowledge and information to improve models.

Participatory modeling has become an essential part of environmental impact assessment and planning in the field of water resources management (Hare 2011; Seidl 2015). Hare (2011) defined PM as "a diverse range of modeling activities whose common element is that they involve stakeholders in one or more stages of the modeling process, from data collection through to model construction and use." One reason for the increased popularity of PM in recent years is the experience that models developed by scientists for scientific purposes are often not suitable for practical management due to their often (too) high complexity, low user friendliness, and lack of problem/solution orientation (e.g., Borowski and Hare 2007; Hare 2011; Horlitz 2006; Kok et al. 2008; Myšiak et al. 2008; Webler and Tuler 2006). Participation is considered a key concept of bridging the gap between modelers and stakeholders and eventually between science and society (Andersson et al. 2008; Carmona et al. 2013b; Simmons et al. 2012; Voinov and Bousquet 2010). This is particularly true in the field of water resources due to the existence of water in all environmental compartments, its mobility, and its outstanding importance for nature and humans (Jakeman and Letcher 2003; Kelly et al. 2013; Kragt et al. 2011; Liu et al. 2008).

Transdisciplinary research ${ }^{1}$ (TD) is centered around real-world problems and current societal objectives and aims to benefit society by contributing solutions for its transformation processes (Stauffacher 2011). TD proposes joint problem-solving by representatives of the science community and legitimized decision makers (Naustdalslid 2011; Pohl 2011; Pohl and Hadorn 2007; Scholz et al. 2006). TD thus inherently involves the participation of stakeholders (in the broader sense of the word, comprising experts, decision makers and representatives from the public at large), the explicit integration of different types of knowledge, and the consideration of different values and interests (Voinov et al. 2014). In general terms, TD is fundamentally about mutual learning between science and society and embodies the mission of science with rather than just for society (Seidl et al. 2013). Whereas TD starts with scientists and stakeholders reaching basic consensus on project goals, the extent of stakeholder participation can

\footnotetext{
${ }^{1}$ Multiple interpretations of "transdisciplinarity" are prevailing, e.g., Pohl (2011), Pohl and Hadorn (2007) and Scholz et al. (2006).
}

vary between projects and/or project stages, depending upon goal and scope of the project(s) and financial and temporal constraints.

\section{PM case study}

In this paper, we focus on the GLOWA-Danube (GD) project, one of five international projects (http://www. glowa.org/) financed by the German Ministry of Education and Research (BMBF). GD was carried out by an interdisciplinary consortium of 17 research groups between 2001 and 2011. The project aimed to provide an integrated approach to predicting global change impacts to the hydrological cycle in the Upper Danube Catchment (UDC) (Fig. 1). It addressed global change, defined as the sum of processes altering "the current and future living conditions of people" (http://www.glowa.org/). GD placed a strong focus on climate changes, but was most interested in its various feedbacks with other natural and societal processes of change (demographic change, economic change, changes in resource use, etc.).

The consortium mainly comprised university-based research groups and a few consultants, as well as a state agency. Cooperation with stakeholders throughout the project was explicitly demanded by the BMBF "in order to secure their involvement when the time comes to apply the research findings in practice." Criteria to obtain funding were (among others): "to contribute to the development of transdisciplinary cooperation, high-quality collaboration with partners from public services and private [services] and prospects of implementing research results as applicable technologies, products and services" (BMBF 2008). ${ }^{2}$

After completion of the GD project, the BMBF financed an independent study, which aimed to evaluate the outcomes of the stakeholder dialogue in all five GLOWA projects and other BMBF programs (Maschke et al. 2013). ${ }^{3}$ This study focused on the implementation of the GLOWA projects' results in practical management and how they were used after the projects were terminated. This study's results are somewhat disillusioning, as they showed that the instruments developed by the five project consortia were not used to a large extent. DANUBIA, the integrated simulation and decision support tool developed by the project GLOWA-Danube, was never used outside the group of model developers. The IÖW-study lists a number of reasons for the limited transfer between research and practice. Among the reasons derived from interviews with

\footnotetext{
2 http://www.ptdlr-klimaundumwelt.de/en/242.php.

3 This publication (in German) provides a short summary only; the full report of the study carried out by Institut für ökologische Wirtschaftsforschung (IÖW) is unfortunately not available to the public.
} 

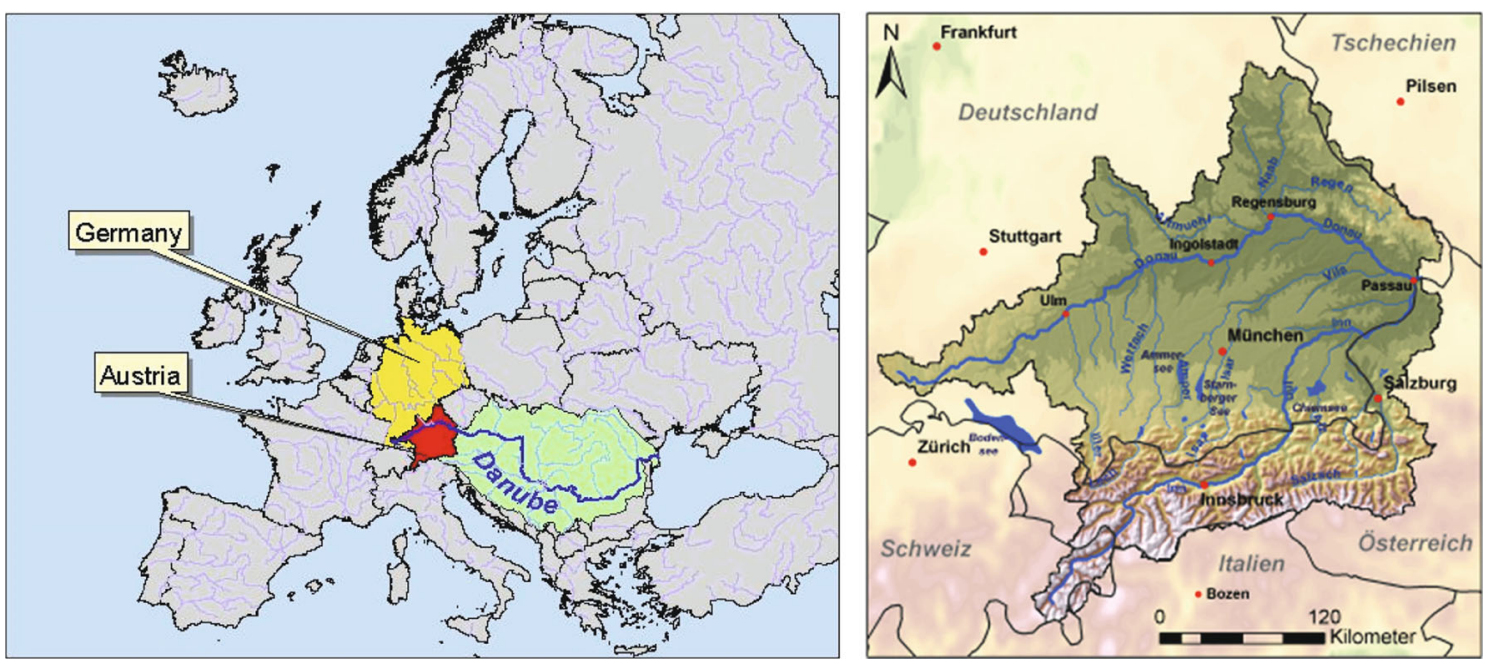

Fig. 1 Case study area-the Upper Danube Catchment. Left (modified from Mauser and Prasch (2016): location of the UDC (red) as headwater catchment of the entire Danube basin (green). Right relief and major geographic features of the UDC (color figure online)

actors from both science and practice, the following seem most relevant for this paper:

- The developed modeling concept was too complex, too difficult to use, and the computational demands too high.

- Practitioners (agencies and ministries) and scientists had different objectives and expectations.

The discussion in this article relates to these findings and provides a more detailed analysis, particularly from the modelers' point of view.

\section{Motivation, scope, and objectives of this article}

In view of the already large and growing number of publications on PM, we avoid those issues that have been welltreated in literature to date and rather focus on aspects not often covered in scientific literature, namely the specific conditions for using $P M$ in the field of global change scenarios and on a complex, integrated regional scale. This means we look specifically at a situation where questions regarding global change and particularly climate change are studied on a regional scale using a fully integrated approach and involving stakeholders. A larger number of papers discuss participatory approaches in relation to climate change on the regional scale. These usually have a narrow focus, e.g., on adaptation, knowledge sharing or the technical design and implementation of participatory approaches (e.g., Bartels et al. 2013; de la Vega-Leinert et al. 2008; Faysse et al. 2014; Huntjens et al. 2010). PM as a tool to assist the development of regional models is presented for example by Richards et al. (2013), Carmona et al. (2013a, b) and Holman et al. (2008). The combination of global change impact assessment as the problem context, integrated models as the tool, and the focus on a regional scale provides a specific problem setting for PM. This setting becomes increasingly important in the attempt to close the gap between global predictions and regional impact assessment and the gap between scientific and stakeholder perspectives in relation to global change. The following context-specific issues frame our analysis:

1. The case study presented here deals with a global change impact analysis in a region where current environmental problems are directly climate related only to a minimal degree (see "Modeling framework and study area"). Climate change may be accepted as a severe global threat but in most instances, is not perceived as an immediate regional one in the UDC. Moreover, the potential effects will not occur within a period of time tangible to a public who is more concerned with present issues (Seidl 2009).

2. Additionally, we examine the specific conditions for the PM set by region-scaled, integrated modeling approaches, which typically face the specific problem of data scarcity paired with high-complexity systems and thus generate results with a high degree of uncertainty (Barthel 2014).

3. Finally, we address the motivation of modelers to become involved in such processes.

In the following sections, we analyze GD's project phases related to PM (but not with respect to other participatory elements of the project). The following questions are addressed:

1. How far does PM lead to better, more accepted models, independent of the type of problem that the models are supposed to deal with? 
2. How far is it possible to use PM to gain simultaneous acceptance by the scientific peer-modeling community and by stakeholders for their use of the models?

3. To what extent and under which conditions are scientists motivated by the objective of gaining stakeholder acceptance and use of their models?

It is important to point out that this paper focuses mainly on the stakeholder dialogue's impact on model development, not on other objectives of this dialogue, such as scenario development, knowledge distribution, networking, and creating problem awareness.

\section{Modeling framework and study area}

The GD project's goal was to develop the integrated modeling system DANUBIA to evaluate the impact of global change on the UDC (Fig. 1). DANUBIA is a fully coupled modeling system developed to study important processes and feedback related to water resources from both the natural and social science perspectives (Ludwig et al. 2003). It consists of 18 separate model components and a central framework that controls data exchange and temporal sequences (Barth et al. 2004; Hennicker et al. 2010). Please see Mauser and Prasch (2016) for a complete description of the framework and all models (Fig. 2).

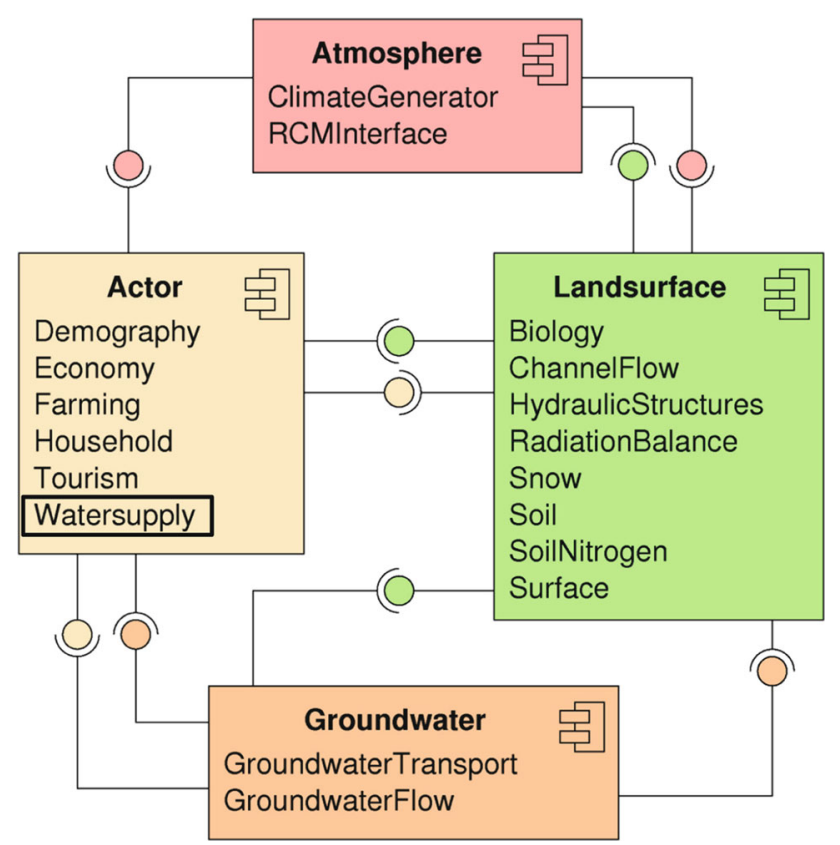

Fig. 2 The four main components and the 18 models of the DANUBIA system. Each entry in the boxes represents one submodel (modified from Mauser and Prasch (2016))
The UDC is a large, heterogeneous, and mountainous catchment with altitudes ranging from 287 to 4049 meters above sea level. Across the catchment, annual precipitation ranges from 650 to over $2000 \mathrm{~mm}$; average annual temperature ranges from -4.8 to $+9{ }^{\circ} \mathrm{C}$ (Mauser and Bach 2009). The population of the UDC is approximately 11.5 million. Water scarcity is largely unknown, with some exceptions, such as in the extremely dry years 1976 and 2003 (Stahl and Tallaksen 2010). Irrigation is not widely applied but steadily increasing. Water quality is usually good, yet several hotspots of contamination from industry and agriculture exist. An average temperature increase of $1.5^{\circ} \mathrm{C}$ over the 1960-2006 period has been determined (Reiter et al. 2012). Precipitation patterns have also changed yet with no clear trend (Reiter et al. 2012). Overall, the climatic changes that could be observed over the last decades had no significant negative impact yet on water resources management (Barthel 2011; Barthel et al. 2011a, b, 2012). Mauser and Prasch (2016) compiled a comprehensive description of the study area, models, scenarios, and results.

With respect to the issues discussed in this article, the physical and technical conditions briefly summarized above show that water resources in the UDC have not been under much pressure yet and there are no observable tendencies that this will change in the near future.

\section{Stakeholder dialogue in GLOWA-Danube}

The GD project's clear goal was to include the stakeholders' perspective on the model and scenario development with the final objective to implement the DANUBIA modeling system in practical management. However, the means of achieving this aim changed throughout three independent project phases which spanned 10 years (see Table 1). Each phase was completed with a peer-reviewed final report. The evaluation results were integrated in the proposal for the next project phase. Thus the development of the stakeholder dialogue described below was a result of a learning process enforced by the funding agency against a backdrop of evolving public perception, increasing scientific knowledge on global change, and a growing body of literature on PM.

Table 1 summarizes the main characteristics of both the model development and the participatory process and the interactions between them through the different project phases. It also reflects different dimensions of the stakeholder process and shows the model development and related stakeholder activities for a selected component, the WaterSupply model. 
Table 1 Brief overview of model development and stakeholder activities during the three phases of the GD project

\begin{tabular}{llll}
\hline $\begin{array}{l}\text { Project phase. } \\
\begin{array}{l}\text { Scope of } \\
\text { description }\end{array}\end{array}$ & $\begin{array}{l}\text { First phase, 2001-2004: Data } \\
\text { acquisition and unstructured } \\
\text { stakeholder activities }\end{array}$ & $\begin{array}{l}\text { Second phase, 2004-2007: Model } \\
\text { consolidation and first approach to a } \\
\text { structured stakeholder dialogue }\end{array}$ & $\begin{array}{l}\text { Third phase, 2007-2010: Model } \\
\text { finalization and structured, externally } \\
\text { moderated stakeholder dialogue }\end{array}$ \\
\hline
\end{tabular}

1 The GLOWA-Danube Project as a whole

1.1 Progress of the development of all model components and the DANUBIA framework

$\begin{array}{cc}\text { Overall goals } & \begin{array}{c}\text { Implementation of all model } \\ \text { components, interfaces, and basic } \\ \text { concepts } \\ \text { Proof of concept }\end{array} \\ \text { Status of the } & \begin{array}{c}\text { Development of basic architecture of } \\ \text { fundamental concepts (space, time, } \\ \text { DANUBIA } \\ \text { framework }\end{array}\end{array}$

Status of model Adaptation of preexisting models to components the framework, development of new model components-very heterogeneous status

Data acquisition for model parameterization and calibration/ verification

Results

Simple, mainly to prove technical capacities of models and framework, simplistic scenarios

Validation of most components and framework impossible

Challenges Different state of model components leads to reduced interaction between models

Data acquisition more difficult than expected. Reluctance of data owners to provide sensitive data
Full implementation of models and framework

Provision of first, coupled-scenario results

Fully developed common framework

Definition and handling of complex scenarios and provision of results

Addition of the DeepActor subframework to model human decisions (Barthel et al. 2008)

Co-existence of fully developed components and components in various stages of development

Growing awareness of limitations, particularly with respect to model integration

Individual components provide meaningful results

All integrative results strongly influenced by "weak components"

Fully developed, complex model components reduce model performance: integrated simulations extremely slow

Scenario definition proves to be more difficult than expected

Increasing links

Stakeholder process part of project plan

A group of scientists from the consortium responsible for the implementation of the process

Main activity: thematic stakeholder workshops with stakeholders from different subthemes (agriculture, water supply, etc.)

Goals Data acquisition

Making the project known

Include stakeholder and user perspectives in model conceptualization
Provision of final results based on complex scenarios

Conclusions about global change impacts on the UDC

Handing over DANUBIA to practice

Refinement and adjustment

Tools to analyze and visualize results

Enhance user friendliness and performance

Almost all model components fully developed

Model integration not fully accomplished-"weak links" substituted by work around

Results from different complex scenarios yet not including all model components

Results are published in the Global Change Atlas of the UDC (Mauser and Prasch 2016)

Constant adjustment and refinement of model components lead to problems with dependent components: the integrated model is never "ready"

Uncertainty and probability of results cannot be quantified

Due to low model performance, only few, integrated scenario simulations are possible

Stakeholder process becomes central to the project plan

External company specializing in stakeholder activities hired

Various, clearly structured activities (see text)

Improve models and scenarios

Increase quality and relevance of results

Make DANUBIA usable and useful (see text) 
Table 1 continued

\begin{tabular}{|c|c|c|c|}
\hline $\begin{array}{l}\text { Project phase. } \\
\text { Scope of } \\
\text { description }\end{array}$ & $\begin{array}{l}\text { First phase, 2001-2004: Data } \\
\text { acquisition and unstructured } \\
\text { stakeholder activities }\end{array}$ & $\begin{array}{l}\text { Second phase, 2004-2007: Model } \\
\text { consolidation and first approach to a } \\
\text { structured stakeholder dialogue }\end{array}$ & $\begin{array}{l}\text { Third phase, 2007-2010: Model } \\
\text { finalization and structured, externally } \\
\text { moderated stakeholder dialogue }\end{array}$ \\
\hline Challenges & $\begin{array}{l}\text { Unclear to what degree global change } \\
\text { would present a problem to the UDC } \\
\text { Dialogue with stakeholders based on } \\
\text { vague and sometimes over-confident } \\
\text { promises made by the modelers and } \\
\text { also vague (and unrealistic) } \\
\text { expectations by the stakeholders }\end{array}$ & $\begin{array}{l}\text { Low interest from stakeholders, no } \\
\text { clear stakeholder identification } \\
\text { strategy } \\
\text { Stakeholder dialogue not recognized } \\
\text { as a central part of the project by } \\
\text { scientists }\end{array}$ & $\begin{array}{l}\text { Model component and framework } \\
\text { development advanced limited } \\
\text { possibilities (flexibility) to respond to } \\
\text { stakeholder suggestions } \\
\text { Regional model unable to provide the } \\
\text { local results of high temporal } \\
\text { resolution in which most stakeholders } \\
\text { are interested }\end{array}$ \\
\hline Results & $\begin{array}{l}\text { Unclear } \\
\text { Identification of groups of potentially } \\
\text { interested stakeholders } \\
\text { Improved access to data }\end{array}$ & $\begin{array}{l}\text { Decision to approach the stakeholder } \\
\text { dialogue in a more professional in } \\
\text { the third phase } \\
\text { Decision to include the main state } \\
\text { agency as a project partner }\end{array}$ & $\begin{array}{l}\text { Difficult to evaluate } \\
\text { Many lessons were learned yet the } \\
\text { ultimate goals were not reached } \\
\text { (Maschke et al. 2013) } \\
\text { The project was terminated, and the } \\
\text { consortium split up and moved without } \\
\text { performing a concluding evaluation }\end{array}$ \\
\hline
\end{tabular}

\section{The WaterSupply model}

2.1 Progress of the development of the WaterSupply model component

Implementation Development of a completely new model component

Results None

Difficulties

Restricted access to data about water supply companies (WSCs), partly because of an ongoing discussion on liberalization/privatization of the water supply sector
Fully functional model, yet without "decision-making" capability (see Barthel et al. 2005)

Parallel development of a DeepActor WaterSupply model

Validation for past periods partly successful

Development of a concept to directly transform abstract model results into simple categories of good/bad (Barthel 2008, Barthel et al. 2011, Barthel et al. 2012)

Model results acceptable at a regional level but not at the level of individual WSCs

No access to data/information needed to carry out realistic decision making

2.2 Progress of the stakeholder process arranged specifically by the WaterSupply developer group

Organization Meetings with individual stakeholders and agencies

Network meetings: Workshops with participants, mainly from ministries and agencies, to discuss model concepts and goals

Materials presented to stakeholders

Problem descriptions, first ideas about model concepts, results from individual tests and basic simulations

Challenges
Many data owners are reluctant to provide sensitive data in view of unclear results

Stakeholders want to see results first, before they commit to being involved
Contacts in various forms with WSCs and other stakeholders to ask for data and advice

Two large surveys (questionnaires) with 1800 WSCs about technical and economic questions

First results from coupled simulations (validation with observed data)

Concepts of the decision-making component

Low return from questionnaires

Loss of interest from main stakeholders as no "convincing" results can be provided

Global change is not considered a main problem
Fully implemented, including decisionmaking component

Results for various complex scenarios (e.g., Barthel et al. 2012; Reiter et al. 2012) with relatively low spatial and temporal resolution

The decision-making component of the model could not be validated against observed data

Meetings with supra-regional agencies

Otherwise, only through the common, project-wide, moderated stakeholder process

Results from the complex scenario simulations

Presentation of model concepts

Results too regional and general for local stakeholders, too little detail of results

Model too complex and slow for regional stakeholders

Large WSCs and agencies conduct their own global change research 
Table 1 continued

\begin{tabular}{llll}
\hline $\begin{array}{l}\text { Project phase. } \\
\begin{array}{l}\text { Scope of } \\
\text { description }\end{array}\end{array}$ & $\begin{array}{l}\text { First phase, 2001-2004: Data } \\
\text { acquisition and unstructured } \\
\text { stakeholder activities }\end{array}$ & $\begin{array}{l}\text { Second phase, 2004-2007: Model } \\
\text { consolidation and first approach to a } \\
\text { structured stakeholder dialogue }\end{array}$ & $\begin{array}{l}\text { Third phase, 2007-2010: Model } \\
\text { finalization and structured, externally } \\
\text { moderated stakeholder dialogue }\end{array}$ \\
\hline $\begin{array}{c}\text { Stakeholder } \\
\text { impact on } \\
\text { model } \\
\text { development }\end{array}$ & $\begin{array}{c}\text { Low, through direct input } \\
\text { of data availability }\end{array}$ & $\begin{array}{l}\text { Very limited } \\
\text { Stakeholders point out deficiencies } \\
\text { that can partly be removed }\end{array}$ & $\begin{array}{c}\text { See "Improvements of model concepts, } \\
\text { model parameterization, and scenarios: } \\
\text { examples from WaterSupply model" }\end{array}$
\end{tabular}

Readers interested in more detail are referred to (Mauser and Prasch 2016) and the references listed in "Modeling framework and study area". More information on the open source modeling system DANUBIA is also available online at http://www.glowa-danube.de/eng/opendanubia/ opendanubia.php (partly in German)

\section{First and second phases of stakeholder involvement}

The stakeholder dialogue in the first phase of the project (2001-2004) was characterized by a vagueness of concepts, expectations, and knowledge at all levels. It was unclear to both modelers and stakeholders what kind of models the consortium would finally be able to develop. Furthermore, in 2001, Global Change was not seen as a threat or issue of relevance in the UDC by many outside the scientific community. For the scientists, the difficulty in accessing the huge amounts of data needed was unexpected, as was the stakeholders' minimal awareness of global change. Also, in 2001, a great portion of the large body of literature on transdisciplinarity and PM mentioned above did not yet exist. The scientific modeling community was still (over-)confident that it would be able to improve models to the degree that they could give reliable, detailed answers and provide decision makers and other stakeholders with the tools needed to tackle global change.

In the second phase (2004-2007), a more structured dialogue was envisioned, but both modelers and stakeholders were reserved and strongly focused upon possible model outcomes. In hindsight, it seems that both sides were insecure with respect to the achievable quality of model results and became distracted from the initial goal of defining use-cases as a basis for model development. It did become apparent to the scientists that they lacked the competence to organize a stakeholder dialogue on their own, and it was decided to commission an external, professional company to organize and moderate a stakeholder dialogue in the third phase (see "Third phase: a structured, externally moderated stakeholder dialogue").

\section{Third phase: a structured, externally moderated stakeholder dialogue}

In the beginning of the third phase (2007-2010), the prerequisites for stakeholder involvement had improved significantly, specifically in socioeconomic actor modeling-a feature that the scientists regarded as essential-because according to their own conviction, it added a new dimension to planning and management under conditions of change.
Actor models for all sectors were implemented (Barthel et al. 2008), parameterization for the entire catchment was completed, simple scenarios were developed, and scenario and validation results were available. The third phase was intended to be the application and validation phase of the DANUBIA modeling system. The system should be used to run scenario simulations to provide meaningful results. This phase also included the transition from the concept's technical proof to a ready-to-use application.

At this time, IFOK $\mathrm{GmbH}^{4}{ }^{4}$ an external, professional consultant specializing in stakeholder dialogues, was mandated to organize the stakeholder process. The intent was to tailor the dialogue to the systematic development of scenarios and the assessment of both these scenarios and the simulation results and their implications. Going further, the dialogue sought the acceptance of potential users of the DANUBIA modeling system and its results. The IFOK aligned and conceptualized the process according to the following goals and tasks of the stakeholder dialogue:

- Establish the DANUBIA modeling system as a support system for decisions The stakeholder dialogue aimed to inform decision makers about the model and to provide an arena for them to voice their feedback and suggestions for the GD project.

- Improve the quality and relevance of the results The stakeholder dialogue had the task of guiding the formulation and assessment of scenarios in conjunction with the stakeholders.

- Support the development of adaptation strategies The stakeholder dialogue was intended to enable a crosssector discussion of the project results and to anticipate conflicts and debate solution options.

The following questions were therefore central to the discussion process with the stakeholders:

- What should GD provide to become more relevant for stakeholders?

\footnotetext{
${ }^{4}$ http://www.ifok.de/en/.
} 
Fig. 3 The GLOWA-Danube stakeholder dialogue in the project's third phase (modified from Mauser and Prasch 2016)

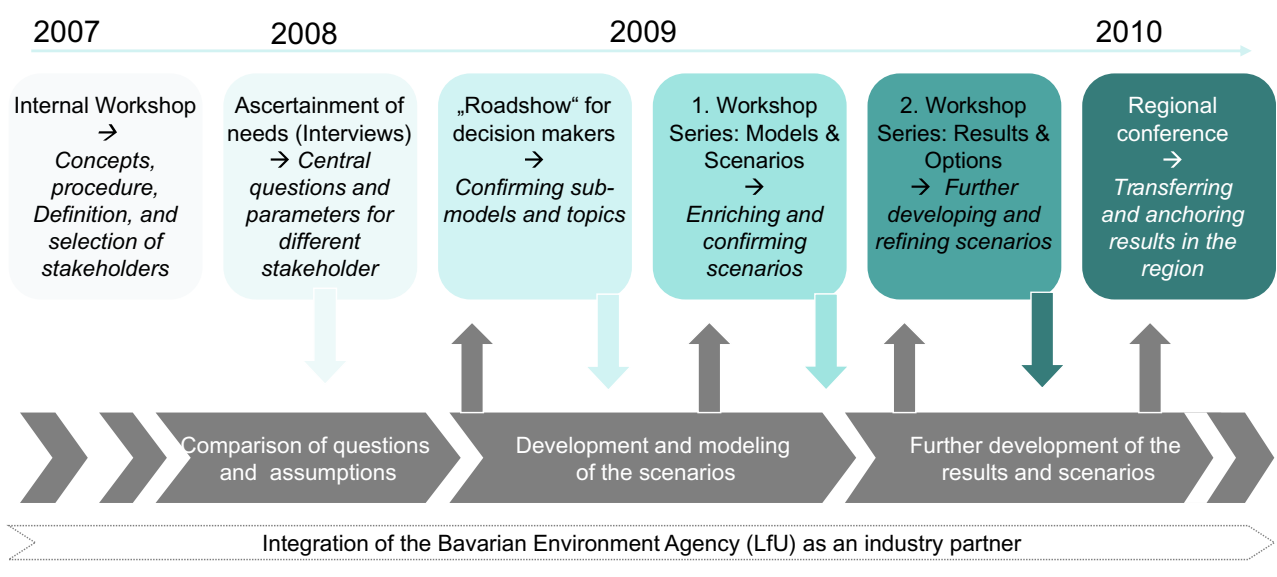

- In what ways can the DANUBIA modeling system provide solutions to concrete questions, for example, regarding long-term investment decisions for river basin planning in terms of the EU Water Framework Directive or regarding the development of adaptation strategies for climate change?

- In view of the project sustainability and relevance to practice, the question of how to regionally establish and implement the GD results was addressed.

The stakeholder dialogue for GD was designed as a continual and iterative process between stakeholders and scientists in terms of transdisciplinary research. Open communication was ensured in both directions-from scientists to stakeholders and vice versa. As a first step, the relevant stakeholders were identified. In the case of water supply (see examples presented in "Improvements of model concepts, model parameterization, and scenarios: examples from WaterSupply model" as well as Table 1), many stakeholders had already been approached in the previous phases in the course of data acquisition and unstructured dialogue. As water supply is a cross-sector activity, stakeholders from policy, administration, and economic sectors, civil society, and civic organizations involved in water management, agriculture and forestry, energy production, shipping, water supply, and tourism were addressed. Next, stakeholders were considered according to their respective potential roles in the project. These stakeholders included, on the one hand, the potential users of the DANUBIA modeling system and its outcomes and, on the other hand, the decision makers, water users, and other parties concerned that could contribute to the development of scenarios and options for action.

Approximately 275 stakeholders were approached, of whom 90 from 40 institutions were actively included in the activities and events. An additional 30-40 actors were integrated in the process by means of interviews and bilateral discussions. For the design of the dialogue process, the stakeholder involvement was aligned content- and time-wise with both the work steps of the scientists and the current activities of the stakeholders. The close cooperation with the stakeholders also presented a challenge to the scientists, who needed to be continually prepared to accept new suggestions and requests but received valuable inputs for their work in exchange. Further details on the organization of the stakeholder process by IFOK are provided in (Büttner 2016).

The IFOK's role in this process was that of a neutral moderator that provided assistance to both sides-scientists and stakeholders - to advance the dialogue, coordinate the timing of the work, and when needed, ensure responses to inquiries directed at GD ("process motor"). In preparation for the stakeholder dialogue, it was necessary to gain an initial understanding between the subprojects of GD and IFOK. Based on this jointly developed understanding, the central work steps of the stakeholder dialogue were designed and implemented. At the end, the dialogue process involved several, systematically interlinked steps (see Fig. 3). Before and after each step, the stakeholder process was adjusted to the modeling and scenario development process of GD.

In the first step, the needs and expectations of the stakeholders from different activity areas and societal domains were explored with the help of semi-structured interviews. This survey provided GD scientists with insights and the moderators with process-oriented considerations for the further conceptualization of the dialogue. In the second step, selected decision makers were informed of the project and the stakeholder dialogue early on ("roadshow"). Scientist teams organized by theme held mostly half-day, moderated roundtable discussions on-site.

The main dialogue process was built on these two steps and occurred in the form of two thematic workshop series spaced 1 year apart. Each series encompassed three full-day, moderated workshops on the themes of (1) energy and infrastructure, (2) agriculture and forestry, and (3) water supply and tourism.

The first workshop series was intended to confirm the sub-models, serve the cooperative discussion of potential future scenarios and issues, and solicit stakeholder wishes 
and requests addressed to GD. Subsequently, the stakeholder requests were modeled by the scientists and processed for the second workshop series, during which the results were presented. Furthermore, requirements and options for action, the results' implications for policy, and the communication to target audiences were discussed.

During all workshops, the employment of structured techniques (e.g., Metaplan visualization) for discussion moderation made possible or facilitated a goal-oriented exchange between stakeholders and scientists.

\section{Results of analysis of GD stakeholder dialogue}

The results of the dialogue are discussed in relation to the following goals of the modelers:

1. Establish a regional network of global change in relation to water management.

2. Secure acceptance of the developed modeling concepts.

3. Improve model concepts, model parameterization, and scenarios.

\section{Establishing a multisector, regional, global change network}

It is difficult to quantify a network's size and performance and the effectiveness of capacity building. The stakeholder process in GD definitely led to many connections between scientists and local and regional stakeholders. However, some factors prevented a more solid establishment of a sustainable network. First, the majority of GD researchers held temporary positions, financed through the project. Thus, after the project termination, many of the involved scientists moved on to other places and research topics. A considerable part of the established connections among the scientists and between scientists and stakeholders therefore ceased to exist.

A major obstacle to the formation of a stable network connecting scientists and stakeholders was that the DANUBIA modeling system in its fully developed form was never used or implemented by decision makers after the project termination (see "Acceptance of modeling approach and scenarios and utilization of DANUBIA in practical planning and management"). In this regard, despite the increased problem awareness expressed by the stakeholders in a variety of occasions, the huge uncertainty of the model results, paired with relatively moderate, predicted global change impacts, led to the stakeholders' hesitancy to be more actively involved in the research on the topic.

Overall, the stakeholder dialogue addressed the gap between stakeholder expectations (prognosis and basis for decision making) and modeling (complex, unsecured results) and facilitated a fruitful debate on decision making under uncertain conditions. However, this discussion did not create the need for an extended collaboration from which both sides could benefit. From the modelers' perspective, the network's role as an incentive to engage in PM could have been the prospect of follow-up research projects that would be funded, co-funded, or supported by stakeholders; job opportunities (e.g., model maintenance); and access to technical resources and data. As the stakeholders were reluctant to indicate that they were considering any of these options, the modelers' interest in the process decreased considerably over time.

\section{Acceptance of modeling approach and scenarios and utilization of DANUBIA in practical planning and management}

A major dialogue goal was to gain acceptance for the DANUBIA model concept. The modelers' notion of the term acceptance may be biased in its typical usage in the scientific modeling community. An ultimate criterion for a model's (and its outcome's) acceptance in the scientific community is passing the peer-review process of a scientific journal, for example. Numerical performance criteria, that is, the quality of model results in comparison with observed data expressed as numbers (e.g., the Nash-Sutcliffe coefficient), play an important role, as well as sensitivity analysis and other formal tools (e.g., Martinec and Rango 1989). For a model to be scientifically accepted, it is not necessary to be used in practical applications. In this sense, the goal of "gaining acceptance" expressed by modelers might very well have led to confusion among stakeholders. Some stakeholders reported that they "accepted" the approach, but only a few asked the modelers to apply the model to answer specific questions, and the relevant decision makers did not adopt the model for further application.

The modelers' main interest in seeking stakeholder acceptance was to prove to both the scientific community and research-funding organizations that their research was relevant, useful, and applicable. Second, modelers might expect direct benefits from stakeholders through financial support and contracts. The only fully reliable proof of acceptance on the stakeholders' side would have been using the model or asking the modelers to use it to answer specific questions. The latter happened to a moderate extent but based only on selected modules of the DANUBIA modeling system.

"Discussion: challenges of PM in research on global change impacts" further elaborates on this, but it can be mentioned here that the DANUBIA modeling system as a whole was never used by any stakeholder because of its complexity (regarding both its concepts and the level of 
expertise needed to operate it), the uncertainty of scenarios and results, and the regional, long-term scope of the simulations. Thus, the question of acceptance remained theoretical and could not be a major motivation for modelers to commit to the PM process.

\section{Improvements of model concepts, model parameterization, and scenarios: examples from WaterSupply model}

From the modelers' perspective, one main objective was to increase the application potential of the developed models and to obtain feedback on how to improve them. Before the third phase of the GD project the WaterSupply model was "complete" from the modelers' point of view (as published in Barthel et al. 2010). This model version and the results from the scenario simulations were presented to the stakeholders during the various activities described in "Third phase: a structured, externally moderated stakeholder dialogue". The feedback received by the modelers was then used to make changes to the model concept and parameterization. It has to be pointed out here that the majority of the stakeholders who were asked about their opinion/advice related to the model as such did not respond at all. Although a large number showed interest, they finally did not get involved, mentioning lack of time or expertise as the main reason. Only a smaller group of about 10 stakeholders offered constructive and detailed suggestions for improving the model structure, concept, or parameterization.

The following examples show how stakeholder involvement led to changes and adjustments of models and scenarios. To be able to grasp the main essence of the examples, a few words about the WaterSupply model's structure and aims: The central objective of WaterSupply is to simulate the behavior of water supply companies (WSC), which represent the actors simulated in this component, in the event of changing boundary conditions (i.e., changes on the demand or the supply side). The WSC have the possibility to adjust their modes of water extraction and distribution as well as to start collaborations with other WSC based on their preferences and properties (predefined as well as adapting throughout simulations). They can also try to influence consumer behavior, e.g., by issuing warnings. WaterSupply seeks both to optimize the resource use of the WSC and to identify critical regions for which further adaptation of the water supply scheme is necessary (Barthel et al. 2000, Barthel et al. 2008, 2010; Nickel et al. 2005).

\section{Example 1: Model functionality limited to stakeholder suggestion}

In the WaterSupply model, each WSC can have one or more cooperative partners that can be used as additional sources of water in case of water scarcity. The modelers anticipated that under conditions of global change, such solutions would comprise the most widely used approach to overcome the increasing water scarcity, since it was a solution widely applied throughout the previous century. The model was thus equipped with the option to automatically create such cooperative networks. However, the modelers were unsure about the criteria for identifying the best cooperative partners. They hoped to obtain advice by means of the stakeholder dialogue, but it led to an unexpected situation. None of the participating stakeholders from the water supply sector identified networks that could grow automatically as necessary or meaningful, and/or none was able or willing to help with the criteria definition. They feared that such model functionality could be used to identify structural deficits of the prevailing water supply system or could present obstacles to their own plans for future development. In contrast, regional agencies were highly in favor of large networks as these were considered less vulnerable. However, they could not help with defining the criteria because this kind of decision making lay outside their scope of responsibility and competencies. The modelers finally had to deal with a conflict of interest, where improving the acceptance of and usability for one interest group would have significantly weakened that of another, equally important group. As a compromise, the development of cooperative networks could be preconfigured by the users (giving them the possibility to test specific ideas), but no automatic network growth was possible. From a scientific viewpoint, the chosen solution was far less interesting.

\section{Example 2: Clear and justified stakeholder demands that could not be implemented due to technical limitations}

Under the present climatic conditions, WSC in southern Germany can easily satisfy base demands. What they fear most involves dramatically increasing peak loads as a result of specific combinations of weather conditions and periods of the year (e.g., holidays). Thus, one of the most interesting model results from the WSC perspective would have been a prediction of future changes in peak demands and tests whether or not these could be met. However, the structure of the actor components in the DANUBIA modeling system simulating human decisions (Barthel et al. 2008) is based on monthly time steps, and even this time-step length is not really supported by the available data from the past which is often aggregated annually. The typical peak load periods known in the UDC, with several days' duration, can therefore hardly be detected. Thus, there was a clear mismatch between the stakeholders' interests and the model's capabilities. The peak demand option was thus not implemented. 
Example 3: Stakeholder contributions to model validation and improvement or parameterization

The group that developed the water supply component was specifically interested in validating their novel approach to simulating decisions of WSCs under conditions of global change (Barthel 2008, Barthel et al. 2011, Barthel et al. 2012). This validation was not possible based on observed data from the past because information on the reasoning behind decisions was not available to the modelers. Moreover, past decisions were hardly driven by climate change. The idea was to present selected scenarios and their resulting modeled decisions to stakeholders and to ask their opinions about these. This, however, failed to provide the desired outcomes. The problem was that the model results were related to long-term, regional developments (according to the objectives of GD), while most WSCs operate locally. In turn, the regional authorities were not directly involved in local decision making. It also proved to be a main obstacle that the most important reasons for decision making in the UDC's water supply sector were primarily economic and technical and hardly related to long-term climatic changes (with not quantifiable economic consequences). While the approach received considerable scientific interest (expressed in citation counts), the interest from the stakeholder side was close to zero.

The three examples are representative for most discussions between modelers and stakeholders. Two main problems can be depicted:

- Most changes and improvements suggested by stakeholders asked for functionality that the modelers were unable to provide due to technical or data availability constraints. Typically, these constraints resulted from the spatial and temporal resolution chosen for the DANUBIA modeling system. Stakeholders were usually interested in a much higher resolution than the model could provide.

- Stakeholders were usually unable to comment on the validity of the concepts and the results as these were in most cases, outside their own scope of expertise and experience. This was again due to the extremely large spatial and temporal extent of the analysis and the fairly complex and abstract concepts (particularly simulating decisions using actor-based modeling, Barthel et al. 2008).

In summary, a mismatch between the modelers' objectives, scope, and interest and the stakeholders' interest, expertise, and demands led to some degree of frustration on both sides. A systematic analysis of this failure was not performed, but at least on the scientists' side, a "we are just losing valuable time here" notion became clearly visible.

\section{Discussion: challenges of PM in research on global change impacts}

The previous sections presented the process of model development in GD, focusing on the participatory elements of the approach. The model development-related impacts of this stakeholder dialogue (summarized in "Results of analysis of GD stakeholder dialogue") indicated that the PM's main goals were not attained. Most prominently, after the scientific project termination, the DANUBIA modeling system was not utilized in practical management. The acceptance of the DANUBIA modeling system concept also remained low or at least unclear. The overall impact of stakeholder interaction on model development can thus be characterized as relatively minor. We would like to point out again that participatory elements of GD encompassed much more than participatory model development. The achievements of those other elements were positive but are not discussed in this article.

That models developed by scientists remain unused is not uncommon (Borowski and Hare 2007). The PM activities are usually regarded as a way to overcome this problem. The related typical challenges and obstacles have already been addressed in a large number of studies (see e.g., Barreteau et al. 2013; Voinov and Bousquet 2010; Voinov and Gaddis 2008). Here, we focus on issues central to the GD case, involving the prerequisites, challenges, obstacles, and benefits of applying PM in the research on global change impacts by using regional, integrated models.

\section{How can PM contribute to the development of new, complex modeling systems?}

The DANUBIA concept involved complex, process-based scale models with a high spatial and temporal resolution covering a large area, leading to a system with hundreds of inter-dependent variables and complex feedback. The modelers chose this concept to explore all potential impacts of global change on various aspects of the water cycle and to study the feedback between coupled systems and processes. It lies in the nature of things that researchers strive to approach questions this way, aiming at novelty and originality and dissemination of their acquired knowledge in scientific publications.

On the other hand, the majority of studies on PM activities arrive at the conclusion that to be accepted and used by stakeholders, models employed in PM should be simple, robust, and easy to use (e.g., Horlitz 2006; Janssen et al. 2008; Kok et al. 2008; Siebenhüner and Barth 2007; Webler and Tuler 2006). Without attempting to discuss the controversial issue of complexity/simplicity of models any further, we can also mention that 
many authors observe a coupling between uncertainty and complexity (Hare 2011; Krysanova et al. 2007; Van Asselt and Rotmans 2002; Volk et al. 2010). Explaining uncertainties to stakeholders becomes increasingly difficult with increasing complexity of integrated modeling approaches because the impact of uncertainties on results becomes more difficult to follow through an increasing number of interdependent processes.

Had GD's sole goal been to develop an instrument to be used by agencies, dedicated to dealing with a well-defined, known problem, it could easily be determined that the chosen approach was wrong. However, GD's objectives were more diverse (a new scientific methodology was to be developed), and the problem (regional consequences of global change) was a very unspecific one. The question therefore is: "Was the modeling approach chosen by GD wrong because it was too complex, or was it wrong to use a participatory strategy to assist in developing the complex model?"

From the initial perspective of the modelers, the complex GD modeling approach was justified, as the objective was to evaluate a complex problem. During the course of the project, however, it became evident that the modelers had been overly optimistic, e.g., about the possibilities to couple atmospheric and hydrological models (still a largely unsolved problem). They were also too optimistic with respect to the model's abilities to simulate human behavior. But it lies in the nature of a research activity to challenge the existing knowledge by trying what no one has tried be for. From a merely scientific viewpoint, the chosen complexity was well justified.

On the other hand, the project also had the goal to develop problem-solving strategies and to develop tools that were accepted by stakeholders. This objective could not be fully reached. However, it can still not be claimed that the stakeholders' involvement was wrong, as their perspectives on the individual parts of the system, mainly the interfaces of natural sciences and socioeconomic sciences, helped the scientists greatly to conceptualize DANUBIA, if only by helping to detect limitations and deficiencies. This may not have made DANUBIA into an applicable tool, but it will definitely help to develop models in the future. So there is no definite answer to the question raised above: it simply depends on the perspective regarding the process and objectives. Both the stakeholders and the modelers have benefited from the process yet not to the degree that was initially expected.

\section{Structure of a participatory process}

Among the frequent recommendations to achieve successful PM in research projects are to involve stakeholders as early as possible (see e.g., Diez and McIntosh 2009; Hare 2011).
Recommendations range from early in the model-developing phase, over in the research planning (i.e., when developing the project proposal), to engage stakeholders even in the development of the call for proposals.

In GD, a real stakeholder involvement took place only after about 6 years of the 10 -year project. According to the above-listed recommendations, this could be easily identified as a fundamental mistake. However, it might be not that simple. The project's approach in the first phase involved developing an integrated modeling system and proving that it (1) worked, (2) generated meaningful results, and was thus (3) a valuable tool for anyone interested in evaluating the impacts of global change on water and land resources in the UDC. Only in the second phase were stakeholders invited for a discussion of the results, with the goals of adjusting and improving the model and scenario assumptions, completing the database, and most importantly, specifying the concrete questions that the model should address. This seemingly "delayed" timing was foremost a consequence of the problem setting addressed by GD. The analysis conducted in GD did not so much target tackling an existing, visible, and pressing environmental problem as it dealt with potential future problems of unknown nature and magnitude. Evaluating the nature and possible severity of these potential problems was a goal of the model development and its application (see also "How can PM contribute to the development of new, complex modeling systems?"). Regarding stakeholder involvement, this meant that stakeholders first had to be made aware that problems might arise and that they would or might be affected but to an unknown degree.

Again, the discussion returns to the question of which one of PM's multiple goals in GD was the most important. Earlier involvement of stakeholders could have led to more usable models, but these might have lacked scientific soundness. Additionally, a strategy aiming at more usable (less complex) models would have posed an obstacle to accomplishing the scientific goals, for example, the development of a fully integrated platform, new approaches to modeling human decisions, coupling of atmosphere and land-surface models, etc.

\section{Scientists' motivation for PM}

As pointed out in the introduction, participatory processes and PM are increasingly perceived as key to successful implementation of scientific (modeling) results in practical applications. Scientists from all disciplines express widespread consensus on this matter. Funding organizations often prescribe stakeholder involvement and make it a central aspect of research proposal evaluation. Against this background, it might seem that at least the scientists (here, 
modelers) should be highly motivated to use PM and become actively involved.

However, this case is not reflected by the actual status of models developed by scientists. It is frequently pointed out that models are often science-driven rather than user-driven types and do not address real-world issues from potential users' perspective (Borowski and Hare 2007; Kok et al. 2008; Myšiak et al. 2008). Once the processes have been adequately described, scientists are usually satisfied with the models and do not develop them further to solve practical problems (van Delden et al. 2011). This situation is often explained by a lack of understanding between modelers and stakeholders, in particular on the part of the scientists, (e.g., Borowski and Hare 2007; Brugnach et al. 2007; de Kok and Wind 2003; Olsson and Andersson 2006). We argue that it is not necessarily the lack of understanding. The real issue may be that it takes enormous efforts to create usable, stable products from science models and that much of the work needed for this is not regarded as a scientific task and thus not rewarding with respect to career options.

"Willingness to participate" is a key issue of participatory modeling and thus discussed in a large number of publications (e.g., Andersson et al. 2008). However, most of the published works primarily address the stakeholders' willingness to become involved. Only few comment on the benefits of PM for scientists but focus nevertheless on the expectations of the stakeholders (e.g., de la Vega-Leinert et al. 2008). It seems that it is almost taken for granted that scientists are motivated to participate per se, probably because they are usually the ones who initiate PM activities. In terms of analyzing scientists' role in PM, the literature focuses on the ways that scientists choose to carry out PM (e.g., Voinov et al. 2014), their limited insights into decision-making processes (e.g., Borowski and Hare 2007; Hare 2011), or their lack of competence in communication (Horlitz 2006; Kok et al. 2008). McIntosh et al. (2011) list more such deficiencies. Nonetheless, it is hardly discussed whether scientists are really motivated to conduct PM and how this may affect their commitment to the process and finally, the outcome of the PM activity as a whole.

It has been argued in literature on interdisciplinarity that activities outside their own disciplines drastically limit the career options of young scientists without tenure (Froedeman et al. 2010; Roy et al. 2013; Vasbinder et al. 2010). Publications in high impact journals of the author's own discipline are still seen as the most important sign of scientific excellence (Fischer et al. 2011). Young scientists, particularly in the natural sciences, have to build a solid track record, based on publications and citations. Spending much time in interdisciplinary discussions or stakeholder workshops indeed presents an obstacle for most young scientists. Experiences on how transdisciplinary research influences publication output and career options are thus not published yet due to the fact that transdisciplinarity is a rather young concept. As transdisciplinarity can be seen as an extension of interdisciplinarity, it is fair to assume that the findings published on the latter can be applied to the first. It can thus be argued that only a few scientists (usually not young ones in temporary positions) manage to make participation and interdisciplinary approaches their own subject and publish about it. The vast majority needs to publish papers of high disciplinary quality. Reviewers in disciplinary scientific journals and evaluation committees for hiring tenured faculty positions are hardly interdisciplinary and focus on publication numbers, journal impact factors and citation indices. Publishing a (truly) inter- or even transdisciplinary manuscript is tedious and remains a considerable challenge (Schoot Uiterkamp and Vlek 2007; Wood 2012). Collaboration calls for a significant amount of time spent in communication among participants so that all gain at least a basic understanding of the types of theories, methods, data, and analyses used by the others (e.g., Campbell 2005; Lerner et al. 2011; Strang 2007). The majority of researchers are not particularly excited about this side of interdisciplinarity (Bell et al. 2005). Particularly, researchers in their early career stages are discouraged by the disadvantageous, time-consuming, and publication-record limiting aspects of interdisciplinary research (Bruhn 2000).

Then why do scientists opt to use participatory approaches in the first place? One answer might be that interdisciplinarity is increasingly a prerequisite for funding. It is easy to include it in proposals, at least as long as follow-up is not to be expected and no strategies exist to measure the efficiency and the success of such activities (see also Voinov and Bousquet 2010).

\section{Conclusions}

In this article, the participatory elements of the GLOWADanube Project were described and discussed. This project was unique in many ways. The conclusions presented here are therefore not directly applicable to each and every PM activity. We are nevertheless convinced that the lessons learned from GD are of particular value for scientists inexperienced in participatory approaches that wish to develop a new, scientifically exciting methodology which is at the same time applicable and designed to meet the needs of stakeholders. Despite a growing number of useful guidelines to PM (see e.g., Seidl 2015; Voinov and Bousquet 2010; Voinov and Gaddis 2008; Voinov et al. 2014), we observe 
that (natural) scientists remain reluctant or inexperienced with respect to stakeholder involvement. Important current approaches in hydrological sciences [e.g., Panta Rhei, Montanari et al. (2013), Socio-Hydrology, Sivapalan et al. (2012)] do not seem to integrate the wealth experiences that have been published on TD and PM. However, this critique does not devalue PM activities or the approach as such. In contrary we perceive PM as an important contribution to global change and sustainability research.

The GD project was successful in engaging stakeholders in an informative discussion about global change impacts, scenarios, and models for the Upper Danube Catchment. The stakeholder involvement and the result dissemination (particularly the Global Change Atlas of the Upper Danube Catchment, Mauser and Prasch 2016) have clearly contributed to the awareness of global change and its implications for the region. However, the integrated modeling system developed by the project has not been adopted and used by any of the stakeholders to date. Likewise, the PM process had little impact on the model conceptualization, parameterization, and validation. This was not a result of stakeholders' lack of interest or inactivity but of the discrepancy between the concrete stakeholder interests and the questions that could actually be addressed by the model. The enormous complexity and unquantifiable uncertainties also presented a main obstacle to stakeholder adoption of the model.

The lessons learned (key messages) from GD are as follows:

1. The dual goal of developing an applicable, userfriendly and context-specific model (acceptance by stakeholders) that fulfilled the highest scientific standards (acceptance by the scientific community) proved not only unattainable, but also undermined the stakeholder process from the beginning. Time-consuming PM activities are likely to be perceived as an obstacle to accomplishing the scientific goals, whereas stakeholders will be daunted or put off by the complex concepts and scientific terminology. This situation creates frustration, disillusionment, and a lack of willingness to invest in the process on both sides. We conclude that the combination of too many and competing objectives can weaken a PM activity as a whole.

2. To gain acceptance of stakeholders and to maximize the benefits of their contributions to the PM, they need to be involved very early in the process of model development. This is by no means a new insight, but of particular relevance in global change research and when addressing the regional scale. Such research involves large uncertainties, fuzzy problem definitions, manifold feedback loops between nature and humans, and large temporal and spatial scales. Stakeholders should be involved in negotiations regarding project and modeling objectives, system boundaries, etc., and therefore long before concrete model design. This requires a process that follows a TD approach (as introduced in "Terminology"), including finding a common understanding of problems, integrating knowledge and values, defining roles and responsibilities within the process, and clearly committing to the task (see also e.g., Voinov et al. 2014). The collaboration of scientists/modelers and stakeholders in an early phase, an open discussion of their respective goals, and a mutual understanding of rationales may prevent disappointment due to unfulfilled expectations. We clearly perceive the risks of consensus failure and process termination in such an early phase. Nonetheless, in our view, such a termination or radical adaptation of the approach and restart are more honest and may avoid years of work on models that will not be used by the initial target actors.

3. An increasing number of scientists from all disciplines is committed to transdisciplinary science and participatory processes. However, it should not be overlooked that there are few incentives to commit to such time-consuming processes, particularly for scientists in their early career stages without tenure. It is not sufficient that research funders acknowledge this. It is necessary for the scientific community itself to find and use new strategies for assessing scientific quality.

\section{Software availability}

The source code of DANUBIA is available under an Open Source License at http://www.glowa-danube.de/eng/open danubia/opendanubia.php.

Acknowledgments GLOWA-Danube was funded by the BMBF (German Federal Ministry of Education and Research) with additional support by the federal states of Bavaria, Baden-Württemberg and Nordrhein-Westfalen. We would like to thank all governmental organizations, private companies and others who supported our work by providing data, models, advice or additional funding and in particular all the stakeholders which got involved in the various ways described in this article. We would like to thank our colleagues from the partner projects within GLOWA-Danube for the cooperation and fruitful discussion. We would like to thank Alexey Voinov and an anonymous reviewer for their valuable comments and suggestions.

Open Access This article is distributed under the terms of the Creative Commons Attribution 4.0 International License (http://creative commons.org/licenses/by/4.0/), which permits unrestricted use, distribution, and reproduction in any medium, provided you give appropriate credit to the original author(s) and the source, provide a link to the Creative Commons license, and indicate if changes were made. 


\section{References}

Andersson L, Olsson JA, Arheimer B, Jonsson A (2008) Use of participatory scenario modelling as platforms in stakeholder dialogues. Water SA 34:439-447

Barreteau O, Bots P, Daniell K, Etienne M, Perez P, Barnaud C, Bazile D, Becu N, Castella J-C, Daré Ws, Trebuil G (2013) Participatory approaches. In: Edmonds B, Meyer R (eds) Simulating social complexity, understanding complex systems, pp 197-234. doi:10.1007/978-3-540-93813-2_10

Bartels WL, Furman CA, Diehl DC, Royce FS, Dourte DR, Ortiz BV, Zierden DF, Irani TA, Fraisse CW, Jones JW (2013) Warming up to climate change: a participatory approach to engaging with agricultural stakeholders in the Southeast US. Reg Environ Change 13:S45-S55. doi:10.1007/s10113-012-0371-9

Barth M, Hennicker R, Kraus A, Ludwig M (2004) DANUBIA: an integrative simulation system for global change research in the Upper Danube Basin. Cybern Syst 35:639-666. doi:10.1080/ 01969720490499425

Barthel R (2011) An indicator approach to assessing and predicting the quantitative state of groundwater bodies on the regional scale with a special focus on the impacts of climate change. Hydrogeol J 19:525-546. doi:10.1007/s10040-010-0693-y

Barthel R (2014) A call for more fundamental science in regional hydrogeology. Hydrogeol J 22:507-510. doi:10.1007/s10040014-1101-9

Barthel R, Nickel D, Meleg A, Trifkovic A, Braun J (2005) Linking the physical and the socio-economic compartments of an integrated water and land use management model on a river basin scale using an object-oriented water supply model. Phys Chem Earth 30:389-397. doi:10.1016/j.pce.2005.06.006

Barthel R, Janisch S, Schwarz N, Trifkovic A, Nickel D, Schulz C, Mauser W (2008) An integrated modelling framework for simulating regional-scale actor responses to global change in the water domain. Environ Modell Soft 23:1095-1121. doi:10.1016/ j.envsoft.2008.02.004

Barthel R, Janisch S, Nickel D, Trifkovic A, Horhan T (2010) Using the multiactor-approach in Glowa-Danube to simulate decisions for the water supply sector under conditions of global climate change. Water Resour Manag 24:239-275. doi:10.1007/s11269009-9445-y

Barthel R, Krimly T, Elbers M, Soboll A, Wackerbauer J, Hennicker R, Janisch S, Reichenau TG, Dabbert S, Schmude J, Ernst A, Mauser W (2011a) Global change impacts on groundwater in Southern Germany-Part 2: socioeconomic aspects. Folgen des Globalen Wandels für das Grundwasser in Süddeutschland-Teil 2: Sozioökonomische Aspekte 16:259-268. doi:10.1007/s00767011-0180-y

Barthel R, Reichenau TG, Muerth M, Heinzeller C, Schneider K, Hennicker R, Mauser W (2011b) Global change impacts on groundwater in Southern Germany-Part 1: natural aspects. Grundwasser 16:247-257. doi:10.1007/s00767-011-0179-4

Barthel R, Reichenau TG, Krimly T, Dabbert S, Schneider K, Mauser W (2012) Integrated modeling of global change impacts on agriculture and groundwater resources. Water Resour Manag 26:1929-1951. doi:10.1007/s11269-012-0001-9

Bell ST, Carss D, Marzano M (2005) Calming troubled waters: making interdisciplinarity. Work Forestry Commission England, Edinburgh

BMBF (2008) GLOWA Globaler Wandel des WasserkreislaufsIHP/ HWRP-Berichte, Koblenz

Borowski I, Hare M (2007) Exploring the gap between water managers and researchers: difficulties of model-based tools to support practical water management. Water Resour Manag 21:1049-1074. doi:10.1007/s11269-006-9098-Z
Brugnach M, Tagg A, Keil F, de Lange WJ (2007) Uncertainty matters: computer models at the science-policy interface. Water Resour Manag 21:1075-1090. doi:10.1007/s11269-006-9099-y

Bruhn JG (2000) Interdisciplinary research: a philosophy, art form, artifact or antidote? Integr Physiol Behav Sci 35:58-66. doi:10. 1007/bf02911166

Büttner H (2016) The Stakeholder Dialogue in the Third Project Phase of GLOWA-Danube. In: Mauser W, Prasch M (eds) Regional assessment of global change impacts-the project GLOWA-Danube, pp 49-53

Campbell LM (2005) Overcoming obstacles to interdisciplinary research. Conserv Biol 19:574-577. doi:10.1111/j.1523-1739. 2005.00058.x

Carmona G, Varela-Ortega C, Bromley J (2013a) Participatory modelling to support decision making in water management under uncertainty: two comparative case studies in the Guadiana river basin, Spain. J Environ Manag 128:400-412. doi:10.1016/j. jenvman.2013.05.019

Carmona G, Varela-Ortega C, Bromley J (2013b) Supporting decision making under uncertainty: development of a participatory integrated model for water management in the middle Guadiana river basin. Environ Modell Soft 50:144-157. doi:10.1016/j. envsoft.2013.09.007

de Kok J-L, Wind HG (2003) Design and application of decisionsupport systems for integrated water management: lessons to be learnt. Phys Chem Earth Parts A/B/C 28:571-578. doi:10.1016/ s1474-7065(03)00103-7

de la Vega-Leinert AC, Schröter D, Leemans R, Fritsch U, Pluimers J (2008) A stakeholder dialogue on European vulnerability. Reg Environ Change 8:109-124. doi:10.1007/s10113-008-0047-7

Diez E, McIntosh BS (2009) A review of the factors which influence the use and usefulness of information systems. Environ Modell Soft 24:588-602. doi:10.1016/j.envsoft.2008.10.009

Faysse N, Rinaudo JD, Bento S, Richard-Ferroudji A, Errahj M, Varanda M, Imache A, Dionnet M, Rollin D, Garin P, Kuper M, Maton L, Montginoul M (2014) Participatory analysis for adaptation to climate change in Mediterranean agricultural systems: possible choices in process design. Reg Environ Change 14:S57-S70. doi:10.1007/s10113-012-0362-x

Fischer ARH, Tobi H, Ronteltap A (2011) When natural met social: a review of collaboration between the natural and social sciences. Interdisc Sci Rev 36:341-358. doi:10.1179/030801811x 13160755918688

Froedeman R, Thompson Klein J, Mitcham C (2010) The Oxford handbook of interdisciplinarity. Oxford University Press, Oxford

Hare M (2011) Forms of participatory modelling and its potential for widespread adoption in the water sector. Environ Policy Gov 21:386-402. doi:10.1002/eet.590

Hennicker R, Bauer SS, Janisch S, Ludwig M (2010) A generic framework for multi-disciplinary environmental modelling, Ottawa, ON, pp 980-994

Holman IP, Rounsevell MDA, Cojacaru G, Shackley S, McLachlan C, Audsley E, Berry PM, Fontaine C, Harrison PA, Henriques C, Mokrech M, Nicholls RJ, Pearn KR, Richards JA (2008) The concepts and development of a participatory regional integrated assessment tool. Clim Change 90:5-30. doi:10.1007/s10584008-9453-6

Horlitz T (2006) The role of model interfaces for participation in water management. Water Resour Manag 21:1091-1102. doi:10. 1007/s11269-006-9100-9

Huntjens P, Pahl-Wostl C, Grin J (2010) Climate change adaptation in European river basins. Reg Environ Change 10:263-284. doi:10. 1007/s10113-009-0108-6

Jakeman AJ, Letcher RA (2003) Integrated assessment and modelling: features, principles and examples for catchment 
management. Environ Modell Soft 18:491-501. doi:10.1016/ S1364-8152(03)00024-0

Janssen JAEB, Hoekstra AY, de Kok J-L, Schielen RMJ (2008) Delineating the model-stakeholder gap: framing perceptions to analyse the information requirement in river management. Water Resour Manag 23:1423-1445. doi:10.1007/s11269-008-9334-9

Kelly RA, Jakeman AJ, Barreteau O, Borsuk ME, ElSawah S, Hamilton SH, Henriksen HJ, Kuikka S, Maier HR, Rizzoli AE, Delden H, Voinov AA (2013) Selecting among five common modelling approaches for integrated environmental assessment and management. Environ Modell Soft 47:159-181. doi:10. 1016/j.envsoft.2013.05.005

Kok JL, Kofalk S, Berlekamp J, Hahn B, Wind HG (2008) From design to application of a decision-support system for integrated river-basin management. Water Resour Manag 23:1781-1811. doi:10.1007/s11269-008-9352-7

Kragt ME, Newham LTH, Bennett J, Jakeman AJ (2011) An integrated approach to linking economic valuation and catchment modelling. Environ Modell Soft 26:92-102. doi:10.1016/j. envsoft.2010.04.002

Krysanova V, Hattermann F, Wechsung F (2007) Implications of complexity and uncertainty for integrated modelling and impact assessment in river basins. Environ Modell Soft 22:701-709. doi:10.1016/j.envsoft.2005.12.029

Lerner DN, Kumar V, Holzkamper A, Surridge BWJ, Harris B (2011) Challenges in developing an integrated catchment management model. Water Environ J 25:345-354. doi:10.1111/j.1747-6593. 2010.00229.x

Liu YQ, Gupta H, Springer E, Wagener T (2008) Linking science with environmental decision making: experiences from an integrated modeling approach to supporting sustainable water resources management. Environ Modell Soft 23:846-858. doi:10.1016/j.envsoft.2007.10.007

Ludwig R, Mauser W, Niemeyer S, Colgan A, Stolz R, Escher-Vetter H, Kuhn M, Reichstein M, Tenhunen J, Kraus A, Ludwig M, Barth M, Hennicker R (2003) Web-based modelling of energy, water and matter fluxes to support decision making in mesoscale catchments - the integrative perspective of GLOWA-Danube. Phys Chem Earth 28:621-634. doi:10.1016/S14747065(03)00108-6

Martinec J, Rango A (1989) Merits of statistical criteria for the performance of hydrological models. Water Resour Bull 25:421-432

Maschke P, Petschow U, Hirschfeld J (2013) Wissenstransfer in der sozio-ökonomischen Wasserforschung: an der Schnittstelle zwischen Forschung und Praxis. Ökologisches Wirtschaften 4:12-13

Mauser W, Bach H (2009) PROMET-large scale distributed hydrological modelling to study the impact of climate change on the water flows of mountain watersheds. J Hydrol 376:362-377. doi:10.1016/j.jhydrol.2009.07.046

Mauser W, Prasch M (2016) Regional assessment of global change impacts-the project GLOWA-Danube. Springer International Publishing, New York

McIntosh BS, Ascough JC, Twery M, Chew J, Elmahdi A, Haase D, Harou JJ, Hepting D, Cuddy S, Jakeman AJ, Chen S, Kassahun A, Lautenbach S, Matthews K, Merritt W, Quinn NWT, Rodriguez-Roda I, Sieber S, Stavenga M, Sulis A, Ticehurst J, Volk M, Wrobel M, van Delden H, El-Sawah S, Rizzoli A, Voinov A (2011) Environmental decision support systems (EDSS) development—challenges and best practices. Environ Modell Soft 26:1389-1402. doi:10.1016/j.envsoft.2011.09.009

Montanari A, Young G, Savenije HHG, Hughes D, Wagener T, Ren LL, Koutsoyiannis D, Cudennec C, Toth E, Grimaldi S, Bloschl G, Sivapalan M, Beven K, Gupta H, Hipsey M, Schaefli B, Arheimer B, Boegh E, Schymanski S, Di Baldassarre G, Yu B,
Hubert P, Huang Y, Schumann A, Post DA, Srinivasan V, Harman C, Thompson S, Rogger M, Viglione A, McMillan H, Characklis G, Pang Z, Belyaev V (2013) "Panta Rhei-Everything Flows": change in hydrology and society-the IAHS Scientific Decade 2013-2022. Hydrol Sci J 58:1256-1275. doi:10.1080/02626667.2013.809088

Myšiak J, Brown JD, Jansen JML, Quinn NWT (2008) Environmental policy aid under uncertainty. In: Jakeman AJ, Voinov AA, Rizzoli AE, Chen SH (eds) Environmental modelling, software and decision support: state of the art and new perspective. Elsevier, Amsterdam, pp 87-100

Naustdalslid J (2011) Climate change - the challenge of translating scientific knowledge into action. Int J Sustain Dev World Ecol 18:243-252. doi:10.1080/13504509.2011.572303

Nickel D, Barthel R, Braun J (2005) Large-scale water resources management within the framework of GLOWA-Danube-the water supply model. Phys Chem Earth 30:383-388. doi:10.1016/ j.pce.2005.06.004

Olsson JA, Andersson L (2006) Possibilities and problems with the use of models as a communication tool in water resource management. Water Resour Manag 21:97-110. doi:10.1007/ s11269-006-9043-1

Pohl C (2011) What is progress in transdisciplinary research? Futures 43:618-626. doi:10.1016/j.futures.2011.03.001

Pohl C, Hadorn GH (2007) Principles for designing transdisciplinary research-proposed by the Swiss Academies of Arts and Science. oekom, Munich

Reiter A, Weidinger R, Mauser W (2012) Recent climate change at the Upper Danube-A temporal and spatial analysis of temperature and precipitation time series. Clim Change 111:665-696. doi:10.1007/s10584-011-0173-y

Richards R, Sano M, Roiko A, Carter RW, Bussey M, Matthews J, Smith TF (2013) Bayesian belief modeling of climate change impacts for informing regional adaptation options. Environ Modell Soft 44:113-121. doi:10.1016/j.envsoft.2012.07.008

Roy ED, Morzillo AT, Seijo F, Reddy SMW, Rhemtulla JM, Milder JC, Kuemmerle T, Martin SL (2013) The elusive pursuit of interdisciplinarity at the human-environment interface. Bioscience 63:745-753. doi:10.1525/bio.2013.63.9.10

Scholz RW, Lang DJ, Wiek A, Walter AI, Stauffacher M (2006) Transdisciplinary case studies as a means of sustainability learning. Int J Sustain High Educ 7:226-251

Schoot Uiterkamp AJM, Vlek C (2007) Practice and outcomes of multidisciplinary research for environmental sustainability. J Soc Issues 63:175-197

Seidl R (2009) Eine Multi-Agentensimulation der Wahrnehmung wasserbezogener Klimarisiken [A multi-agent simulation of the perception of water related climate change risks] Metropolis, Marburg

Seidl R (2015) A functional-dynamic reflection on participatory processes in modeling projects. Ambio. doi:10.1007/s13280015-0670-8

Seidl R, Brand FS, Stauffacher M, Krutli P, Le QB, Sporri A, Meylan G, Moser C, Gonzalez MB, Scholz RW (2013) Science with society in the anthropocene. Ambio 42:5-12. doi:10.1007/ s13280-012-0363-5

Siebenhüner B, Barth V (2007) The role of computer modelling in participatory integrated assessments. Environ Impact Assess Rev 25:367-389

Simmons CT, Hunt RJ, Cook PG (2012) Using every tool in the toolbox. Ground Water 50:323. doi:10.1111/j.1745-6584.2012.00920.x

Sivapalan M, Savenije HHG, Bloschl G (2012) Socio-hydrology: a new science of people and water. Hydrol Process 26:1270-1276. doi:10.1002/hyp.8426

Stahl K, Tallaksen LM (2010) RCM simulated and observed hydrological drought: a comparison of the 1976 and 2003 events in Europe. IAHS-AISH Publication 340, pp 150-156 
Stauffacher M (2011) Umweltsoziologie und Transdisziplinarität. In: Gross M (ed) Handbuch Umweltsoziologie. VS Verlag, Wiesbaden, pp 259-276

Strang V (2007) Integrating the social and natural sciences in environmental research: a discussion paper. Environ Dev Sustain 11:1-18. doi:10.1007/s10668-007-9095-2

Van Asselt MBA, Rotmans J (2002) Uncertainty in integrated assessment modelling. From positivism to pluralism. Clim Change 54:75-105

van Delden H, Seppelt R, White R, Jakeman AJ (2011) A methodology for the design and development of integrated models for policy support. Environ Modell Soft 26:266-279. doi:10.1016/j.envsoft.2010.03.021

Vasbinder JW, Andersson B, Arthur WB, Boasson M, de Boer R, Changeux JP, Domingo E, Eigen M, Fersht A, Frenkel D, Rees M, Groen T, Huber R, Hunt T, Holland J, May R, Norrby E, Nijkamp P, Lehn JM, Rabbinge R, Scheffer M, Schuster P, Serageldin I, Stuip J, de Vries J, van Vierssen W, Willems R (2010) Transdisciplinary EU science institute needs funds urgently. Nature 463:876. doi:10.1038/463876a
Voinov A, Bousquet F (2010) Modelling with stakeholders. Environ Modell Soft 25:1268-1281. doi:10.1016/j.envsoft.2010.03.007

Voinov A, Gaddis EJB (2008) Lessons for successful participatory watershed modeling: a perspective from modeling practitioners. Ecol Model 216:197-207. doi:10.1016/j.ecolmodel.2008.03.010

Voinov A, Seppelt R, Reis S, Nabel JEMS, Shokravi S (2014) Values in socio-environmental modelling: persuasion for action or excuse for inaction. Environ Modell Soft 53:207-212. doi:10. 1016/j.envsoft.2013.12.005

Volk M, Lautenbach S, van Delden H, Newham LT, Seppelt R (2010) How can we make progress with decision support systems in landscape and river basin management? Lessons learned from a comparative analysis of four different decision support systems. Environ Manag 46:834-849. doi:10.1007/s00267-009-9417-2

Webler T, Tuler S (2006) Four perspectives on public participation process in environmental assessment and decision making: combined results from 10 case studies. Policy Stud J 34:699-722. doi:10.1111/j.1541-0072.2006.00198.x

Wood WW (2012) Reductionism to integrationism: a paradigm shift. Ground Water 50:167. doi:10.1111/j.1745-6584.2011.00900.x 